\title{
Socioeconomic and work related determinants of pregnancy outcome in southern Thailand
}

Pitchaya Tuntiseranee, Jorn Olsen, Virasakdi Chongsuvivatwong, Somnuek Limbutara

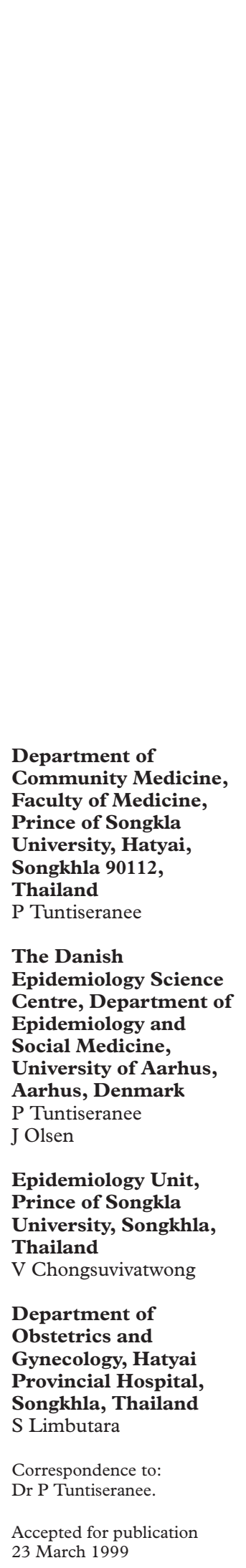

Abstract

Study objective-To examine the effect of socioeconomic status on pregnancy outcome in an urbanised area in a rapidly developing country.

Methods-A cohort of 1797 pregnant women who attended antenatal care clinics at the two 700 bed hospitals in Hatyai city was recruited from September 1994 to November 1995. The pregnant women were followed up from the 17 th week of gestation until delivery. The socioeconomic indicators selected were family socioeconomic status, maternal education, maternal occupation, family income and work exposure characteristics based upon Karasek's job content questionnaires. Pregnancy outcomes were birth weight, low birth weight, small for gestational age and preterm delivery.

Main results-Mean birth weight correlated with socioeconomic status and income but after adjustment for parity, maternal age and height, weight at delivery day, baby sex, obstetrical complications and antenatal care utilisation, only tions and antenatal care utilisation, only family income remained correlated with birth weight. No association with any socioeconomic status indicators was found when using dichotomous outcome (low birth weight, small for gestational age or preterm delivery). Only high psychological job demand was associated with small for gestational age. Confounder adjustment indicated that the observed social status differences in pregnancy outcomes were mainly attributable to mother's characteristics and antenatal service use.

Conclusions-Socioeconomic indicators Conclusions-Socioeconomic indicators fetal growth or preterm delivery in this study, which recruited mainly lower or middle class women. Karasek's psychological job demand was only weakly correlated with small for gestational age infant. (F Epidemiol Community Health 1999;53:624-629)

Low birthweight (LBW) infants constitute a major public health problem in both developed and developing countries as it is a strong determinant of perinatal death. ${ }^{1}$ Lower social class has consistently been associated with high infant mortality rate and low birth weight in a number of countries. ${ }^{2-5}$ It is furthermore well known that maternal weight and height, body mass index, parity, obstetrical complications and inadequate health care play a part. ${ }^{6-8}$ However, studies on socioeconomic status (SES) do not give coherent results. Some studies have shown a linear relation between social class and birth weight but others have not or reported only small differences. ${ }^{9-11}$ The contradiction can be explained by the use of different SES indicators and different birth outcome measurements. ${ }^{11} 12$ Some researchers reported on birth weight, ${ }^{13}{ }^{14}$ others on $\mathrm{LBW}^{15}$ or smal for gestational age $(\mathrm{SGA})^{16}$ and preterm delivery. ${ }^{17}$

LBW can be attributable to prematurity or retarded intrauterine growth or a combination of both. Birth weight adjusted for gestational week measures growth retardation on a quantitative scale, while SGA identifies the frequency of newborns with a birth weight below the 10 th iven standard for any given gestational age. Changes in mean birth weight are importan even if there is no change in the frequency of LBW or SGA, as any increase in the proportion of birth weight below $3500 \mathrm{~g}$ might increase infant mortality. ${ }^{18} 19$ Recent hypotheses even uggest that interference with fetal growth could programme organ functioning and increase the risk of non-insulin dependent diabetes mellitus, hypertension and coronary heart disease. ${ }^{20}$

It is generally accepted that improvements in general social conditions and prenatal and neonatal health care have been the main drive behind improvements in perinatal health in the 20 th century in industrialised countries ${ }^{22}$ Little is known about socioeconomic determinants of fetal growth and preterm delivery in many less industrialised countries, including Thailand. The aim of this study is to estimate the association between SES indicators and birth weight and LBW, SGA and preterm birth, before and after adjusting for materna visits in Thailand, which is a country undergong rapid social transition.

\section{Methods}

DESIGN AND SAMPLING

The study was conducted in Hatyai, a trade and monetary centre of the 14 provinces in southern Thailand. All pregnant women atending routine antenatal care at the two pubic hospitals, Hatyai Hospital and Songklanagarind University Hospital, in Hatyai distric were invited to participate in the study from September 1994 to November 1995. Both hospitals provide maternal child care in an urban area of approximately 300000 inhabitants and he antenatal care coverage by these public sec列 
Table 1 Content of the questionnaires used in exposure assessment

\begin{tabular}{|c|c|c|c|}
\hline Variables & Q17 & Q32 & Qout \\
\hline $\begin{array}{l}\text { Marital status, religion, mother's age, height, father's age } \\
\text { Mother's and father's education } \\
\text { Mother's and father's socioeconomic status } \\
\text { Mother's and father's job title } \\
\text { Mother's and father's income } \\
\text { Obstetrical history } \\
\text { Bleeding per vagina in pregnancy } \\
\text { Medical and obstetrical complication in pregnancy } \\
\text { Urogenital tract infection in pregnancy } \\
\text { Treatment of fertility } \\
\text { Occupational physical activities } \\
\text { Physical and chemical exposures } \\
\text { Occupational job stress (Karasek's } 14 \text { items) } \\
\text { General health questionnaire (12 items) } \\
\text { Domestic work } \\
\text { Activities during leisure time } \\
\text { Smoking and passive smoking, caffeine and beverages consumption } \\
\text { Number of antenatal care visits } \\
\text { Maternal weight at delivery day }\end{array}$ & $\frac{v}{v}$ & $\begin{array}{l}r \\
r \\
r \\
r \\
r \\
r \\
r\end{array}$ & $\sqrt{ }$ \\
\hline
\end{tabular}

Q17, questionnaire used in week 17 of gestation; Q32, questionnaire used in week 32 of gestation; Qout, questionnaire used after delivery.

of private clinics in Hatyai that mainly provide antenatal care for professionals, administrators, clerical staff and people employed in sales. ${ }^{23}$

Women were not included in the study if they were unable to communicate in Thai, unwilling to participate, planned not to give birth at these two hospitals, or had severe psychiatric disorders. Women who had more than one pregnancy within the study period were only recruited in their first pregnancy. We planned to increased the response rate by performing home visits for 200 women who had given birth outside the studied hospitals. Home visits were performed when the estimated delivery date had passed four weeks. Gestational age was calculated using data on child birth date obtained in home visits and last menstrual period. Table 1 gives the content of the questionnaires.

All participants were interviewed in the 17th and 32nd week of gestation (Q17 and Q32) by five female interviewers who had gone through a one week training programme. Shortly after delivery, the researchers assessed the gestational week of the newborn using Dubowitz's fetal maturation score and the third questionnaire (Qout) was completed. The interobserver agreement between the two researchers in assessment of Dubowitz's score showed acceptable agreement ( $\kappa$ statistics $88.03 \%$ ) in a pilot study of 62 newborns.

SOCIOECONOMIC INDICATORS

Measures of SES were based upon occupation, education and income. The categorisation of SES was done before assessing birth outcome and it was based upon education, income and detailed job titles according to the official Thai occupational classification system. Group 1 represents people with an academic background or people holding executive jobs at a high administrative level, for example, doctors, engineers, administrative managers, scientists and people at a lower level of management, for example, paramedic health personnel, priests, artists, large scale wholesalers and retailers. Group 2 includes people with clerical jobs such as typists, clerks, stock checkers, middle sized wholesalers and retailers. Group 3 includes skilled workers, for example, craftsmen, carpenters and industrial foremen. Group 4 is the unskilled workers such as farmers, rubber planters, labourers and workers in the service sector. The family SES was determined by the highest SES group of each couple.

Four indicators besides SES were used; Four indicators besides SES were used,
mother's education, mother's occupation, fammother's education, mother's occupation, famcharacteristics. The mother's income and father's income were combined and then categorised. The lowest income group $(<5000$ baht a month or about 200 US dollars) minimum wage income in this data set. The mother's work exposure characteristics were based on the job stress questionnaire developed by Karase ${ }^{24}$ and the low work control and high physical work demand are characteristics of low status job or manual work. The job stress questionnaire consisted of 14 items - the (Strongly disagree/ Disagree/ Agree/ Strongly agree). Th psychological job demand included nine scored items, for example, learning new things, repetitive work, requiring creativity, personal decision making, requiring a high level of skill, having little freedom in work decision, doing a variety of different things in work, having a lot to say about my work and having an opporunity to develop special abilities. The psychoogical job demand included five scored items, for example, requiring to work very fast requiring to work very hard, requiring physical effort, not being asked to do an excessive amount of work, having enough time to get the $\mathrm{ob}$ done and freedom from conflicting demands.

LBW means infants weighing $2500 \mathrm{~g}$ or less SGA means birth weight below the 10th percentile of weight for a given gestational age according to the Thai standard weight for age distribution. Preterm birth means the delivery efore 37 th gestational week.

\section{ANALYSIS}

The 14 questions concerned maternal work exposure characteristics were based upon summary score for each dimension and divided into quartiles intervals. The 25th, 50th and 100 th percentiles were then grouped into low, middle and high categories.

Of the 2043 women, 1821 had data on pregnancy outcome. Women who had abortions (n $=5)$, multiple births $(n=16)$ and missing data on birth weight $(\mathrm{n}=3)$ were excluded and 1797 women remained in the analysis. Multiple linear regression was used to analyse birth who had a paid job at the first antenatal clinic visit. To adjust for confounding, each SES indicator was added as a single independent variable in the model that included materna age, maternal height, parity, obstetrical complication, sex of newborn and number of prenata aresults are presented before and after controlling for 
Table 2 The correlation matrix of selected socioeconomic indicators in pregnant women who gave birth to singletons, Songkhla, Thailand, 1994-5

\begin{tabular}{lllll}
\hline & $\begin{array}{l}\text { Family } \\
\text { SES }\end{array}$ & $\begin{array}{l}\text { Maternal } \\
\text { education }\end{array}$ & $\begin{array}{c}\text { Maternal } \\
\text { occupation }\end{array}$ & $\begin{array}{c}\text { Family } \\
\text { income }\end{array}$ \\
\hline Family SES & 1.00 & & & \\
Maternaleducation & $0.61^{\star}$ & 1.00 & & \\
Maternal occupation & $0.56^{\star}$ & $0.59^{\star}$ & 1.00 & \\
Family income & $0.49^{\star}$ & $0.42^{\star}$ & $0.35^{\star}$ & 1.00 \\
\hline
\end{tabular}

Maternal education (1) $16+$ years (2) 13-15 years (3) 10-12 years (4) $\leqslant 9$ years. Maternal occupation (1) Professionals and administrators (2) Clerical (3) Trade (4) Agriculture (5) Labour (6) Service. Family income (1) $20001+$ baht (2) $10001-20000$ baht (3) 5001-10 000 baht (4)
$\leqslant 5000$ baht. Family socioeconomic status (SES) (1) high (2) middle (3) lower middle (4) low. ${ }^{*} \mathrm{p}$ value $<0.01$ by Spearma's rank correlation.

potential confounders. Logistic regression was used to analyse LBW, SGA and preterm delivery. Polytomous regression was also performed to estimate the effect of each SES indicator at different cut off points of birth weight $(\leqslant 2500$ g, 2501-3000 g, 3001-3500 g, and $\geqslant 3501 \mathrm{~g})$ and gestational age ( $<37$ weeks, $37-38$ weeks, and $\geqslant 39$ weeks)

The analyses were performed using the STATA version 5 program package.

Results

Altogether 2084 women were recruited in the study. During data collection, Hatyai hospital renewed some of the hospital codes and 41 women were excluded because they could not be linked to the new hospital codes. We visited 200 homes to interview the women who had given birth outside the studied hospital and could contact only 130 mothers. Q17 was completed by 2043 (98\%), Q32 by 1846 $(89 \%)$ and Qout by $1821(87 \%)$.

Occupation was related to physical and psychological exposure at work, job security, personal control in the work environment and social status. Education is considered to be related to health behaviour, and income may provide access to medical care facilities and social benefits. ${ }^{25}$ All socioeconomic indicators are significantly correlated, and the correlation is strong for maternal education, materna is strong for The percentage of women who married men with a higher SES in this study was $26 \%$ and $11.2 \%$ married a husband with lower SES (data not shown).

The liveborn infants in this study had a mean birth weight of $3082 \mathrm{~g}$ (range 1000 to 4750 ) and a mean gestational age of 38.9 weeks (range 24 to 42). The proportions of LBW, $\mathrm{SGA}$ and preterm delivery were $8.9 \%, 2.7 \%$ and $4.9 \%$ respectively.

Table 3 shows the distribution of the birth outcome by maternal sociodemographic and general health characteristics. The mean birth weight was low in young mothers, women with low gestational weight at delivery, women of short stature, nullipara, women with previous preterm or LBW delivery or women who had less than eight visits to a prenatal care clinic. Male new borns had a mean (SD) birth weight of 3129 (461) g and female new borns of 3028 The percentage of young and short

Table 3 Mean birth weight, low birth weight (LBW), small for gestational age (SGA) and preterm delivery by maternal characteristics in irth weight, low birth weight (LBW), small for gestational age (SGA)

\begin{tabular}{|c|c|c|c|c|c|}
\hline Variables & Births (\%) & $\begin{array}{l}\text { Birth weight }(g) \\
(S D)\end{array}$ & $L B W \%$ & $S G A \%$ & Preterm \% \\
\hline \multicolumn{6}{|l|}{ Age (y) \| } \\
\hline$\leqslant 20$ & $427(24)$ & 2995(453) & 11.0 & 3.5 & 6.8 \\
\hline $21-25$ & $557(31)$ & $3116(440)$ & 8.6 & 3.2 & 3.6 \\
\hline & 494(27) & $3090(470)$ & 9.1 & 2.4 & 5.5 \\
\hline $31-35$ & $247(14)$ & $3139(440)$ & 5.7 & 1.2 & 2.5 \\
\hline & $72(4)$ & $3084(433)$ & 8.3 & & \\
\hline \multicolumn{6}{|c|}{ Gestational weight at delivery day $(\mathrm{kg}) \neq \ \|$} \\
\hline$\leqslant 55$ & $424(24)$ & 2912(420) & 14.4 & 4.3 & 5.7 \\
\hline $56-65$ & $655(36)$ & $3100(402)$ & 6.0 & 1.4 & 4.4 \\
\hline $66+$ & $445(25)$ & $3244(439)$ & 4.3 & 2.3 & 2.9 \\
\hline $\begin{array}{l}\text { missing } \\
\text { Heioght }(\mathrm{cm})+\mathrm{s}\end{array}$ & 273(15) & $3039(540)$ & 15.0 & 4.0 & 8.1 \\
\hline \multicolumn{5}{|l|}{ Height $(\mathrm{cm}) \ddagger \S$} & \\
\hline $151-155$ & $600(33)$ & $3072(451)$ & 9.5 & 2.3 & 5.2 \\
\hline $156-160$ & $430(24)$ & $3140(463)$ & 7.0 & 2.1 & 5.7 \\
\hline $161+$ & 161(9) & 3259(399) & 3.7 & 0.0 & 2.5 \\
\hline \multicolumn{6}{|l|}{ Parity $\ddagger \rrbracket$} \\
\hline & $866(48)$ & $3015(443)$ & 11.1 & 3.6 & 5.9 \\
\hline 1 & $649(36)$ & $3134(431)$ & 6.6 & 1.5 & 3.7 \\
\hline \multirow{2}{*}{\multicolumn{6}{|c|}{ Number of prenatal care visit $\ddagger \|$}} \\
\hline & & & & & \\
\hline $5-8$ & $585(33)$ & $3017(465)$ & 12.1 & 3.1 & 6.5 \\
\hline $9-12$ & $786(44)$ & $3126(393)$ & 5.7 & 2.0 & 2.7 \\
\hline $13+$ & $274(15)$ & $3192(407)$ & 3.7 & 1.8 & 2.2 \\
\hline \multirow{2}{*}{\multicolumn{6}{|c|}{$\begin{array}{l}\text { Previous preterm or LBW delivery } ¥ \complement \\
\text { Pros }\end{array}$}} \\
\hline & & & & & \\
\hline no & 1006(56) & $3152(441)$ & 6.1 & 1.6 & 4.0 \\
\hline $\begin{array}{l}\text { yes } \\
\text { Primigravid }\end{array}$ & $74(4)$ & $2830(534)$ & 20.3 & 5.4 & 8.1 \\
\hline \multirow{2}{*}{\multicolumn{6}{|c|}{${ }^{*}$ Medical complications }} \\
\hline & & $3083(450)$ & 8.8 & & \\
\hline $\begin{array}{l}\text { No } \\
\text { Yes }\end{array}$ & $326(18)$ & $3078(470)$ & 9.2 & 3.4 & 6.4 \\
\hline \multicolumn{6}{|c|}{ †Obstetrical complications $\ddagger \|$} \\
\hline & $1266(70)$ & $3124(403)$ & 6.1 & 2.2 & 2.1 \\
\hline Yes & $531(30)$ & 2981(544) & 15.6 & 3.8 & 11.5 \\
\hline
\end{tabular}

${ }^{\star}$ Medical condition as heart and circulatory disease, respiratory disease, haematological disease, immunological disease, gastrointestinal disease, endocrine disease, psychiatric disease, neurological disease, surgical disease, surgery requiring general or spinal anaesthesia. †Hepatitis B and AIDS infection, pre-eclampsia, antepartum haemorrhage, placental previa, abruptio placenta, premature labour pain and ruptured membrane, postterm, tumour, hyperemesis gravidarum. $\neq \$ \| \chi^{2}$ Test for LBW, SGA, Pretern 
Table 4 Birth weight (BW) according to socioeconomic indicators in women who gave birth to singletons, Songkhla,
Thailand, 1994-5

\begin{tabular}{|c|c|c|c|c|c|}
\hline Socioeconomic indicator & Births (\%) & Mean $B W(S D)$ & $p$ value $\neq$ & Adjusted mean $\mathbb{S}(95 \%$ CI) & $p$ value: \\
\hline \multicolumn{6}{|c|}{${ }^{{ }^{*} \text { Family socioeconomic status }^{\mathrm{a}}}$} \\
\hline 1 & $121(7)$ & $3113(391)$ & & $3107(3040,3173)$ & \\
\hline & $228(13)$ & $3118(448)$ & & $3120(3072,3168)$ & \\
\hline & $231(13)$ & $3093(426)$ & & $3068(3021,3116)$ & \\
\hline & $1194(66)$ & $3069(459)$ & & $3076(3055,3097)$ & \\
\hline \multirow{2}{*}{\multicolumn{6}{|c|}{$\begin{array}{l}\text { Unemployed } \\
\text { Maternal education (v) }\end{array}$}} \\
\hline & & & & & \\
\hline $16+$ & $88(5)$ & $3144(448)$ & & $3126(3049,3204)$ & \\
\hline $13-15$ & $84(5)$ & $3144(453)$ & & $3090(30103171)$ & \\
\hline $10-12$ & $440(24)$ & $3084(444)$ & & $3085(3051,3120)$ & \\
\hline \multirow{2}{*}{\multicolumn{6}{|c|}{$\begin{array}{l}\leqslant 9 \\
\text { Maternal occupation }\end{array}$}} \\
\hline & & & & & \\
\hline Professional & $91(5)$ & $3104(370)$ & & $3130(3053,3207)$ & \\
\hline Clerical & $86(5)$ & $3125(507)$ & & $3108(3030,3186)$ & \\
\hline Trader & $179(10)$ & 3075 (483) & & $3077(3022,3131)$ & \\
\hline $\begin{array}{l}\text { Iraaer } \\
\text { Agriculture }\end{array}$ & $395(22)$ & $3085(472)$ & & $3065(3029,3101)$ & \\
\hline $\begin{array}{l}\text { Agricuinture } \\
\text { Labourer }\end{array}$ & $254(14)$ & $3085(399)$ & & $3099(3052,3145)$ & \\
\hline Service & $116(6)$ & 3060 (477) & & $3111(3044,3177)$ & \\
\hline \multirow{2}{*}{\multicolumn{6}{|c|}{$\begin{array}{l}\text { Housewite } \\
\text { Family income (baht) }\end{array}$}} \\
\hline & & & & & \\
\hline $20001+$ & $84(5)$ & $3150(419)$ & & $3109(3032,3185)$ & \\
\hline $10001-20000$ & $263(15)$ & $3121(445)$ & & $3101(3056,3146)$ & \\
\hline $5001-10000$ & $779(43)$ & $3076(464)$ & & $3094(3068,3120)$ & \\
\hline \multirow{2}{*}{\multicolumn{6}{|c|}{$\begin{array}{l}\leqslant 5000 \text { aracteristics } \\
\text { Work chare }\end{array}$}} \\
\hline & & & & & \\
\hline \multicolumn{6}{|l|}{$\begin{array}{l}\text { Work characterersittucs } \\
\text { Physical job demand }\end{array}$} \\
\hline Low & $224(20)$ & $3112(444)$ & & $3132(3085,3180)$ & \\
\hline Moderate & $769(69)$ & $3077(460)$ & & $3071(3045,3097)$ & \\
\hline \multirow{2}{*}{\multicolumn{6}{|c|}{$\begin{array}{l}\text { High } \\
\text { tPsychological iob demand }\end{array}$}} \\
\hline & & & & & \\
\hline $\begin{array}{l}T \\
\text { Low }\end{array}$ & $753(67)$ & $3078(457)$ & & $3078(3051,3104)$ & \\
\hline Moderate & $140(13)$ & $3159(427)$ & & $3159(3097,3221)$ & \\
\hline \multirow{2}{*}{\multicolumn{6}{|c|}{$\begin{array}{l}\text { Hign } \\
\text { tWork control }\end{array}$}} \\
\hline & & & & & \\
\hline & $205(18)$ & $3046(461)$ & & $3048(2998,3099)$ & \\
\hline Moderate & $249(22)$ & $3086(460)$ & & $3076(3030,3122)$ & \\
\hline Low & $667(60)$ & 3097 (449) & 0.257 & $3100(3073,3128)$ & 0.069 \\
\hline
\end{tabular}

${ }^{1} 16$ missing, ${ }^{b} 6$ missing. ${ }^{\star}$ Family socioeconomic status; $1=$ High $2=$ Upper middle $3=$ Middle $4=$ Low. $\nmid$ Low $=\leqslant 50$ th percentile, Moderate $=51 \mathrm{th}-75 \mathrm{~h}$ percentile, High $=\geqslant 76$ th percentile. $\neq \mathrm{p}$ value by test for trend. . SAdjusted for parity, maternal height, matesquare of gestational age.

stature mothers was higher in women with limited education and low social class. The percentage of obstetrical complications during pregnancy was reported highest among wome with the best education and highest SES. Less than one per cent of the women in this study smoked cigarettes or drank alcohol.

Table 4 shows that unadjusted birth weight correlates with the lower level of each SES indicator. After controlling for the potential determinants stated in the footnote of table 4 the relation between each socioeconomic indicator and birth weight remained the same but the magnitude decreased. Women with a high level of work control, however, gave birth to new borns with a low mean birth weight. Women with nine years or less of education had an infant with a mean birth weight of $72 \mathrm{~g}$ an infant with a mean birth weight of $72 \mathrm{~g}$
below that of women with 16 years or more of education. After adjustment for confounders, the difference, however, diminished to $49 \mathrm{~g}$. The proportion of highly educated women $(\geqslant 16$ years) who had a high job demand was $35.2 \%$ compared with $13.2 \%$ among women with $13-15$ years of education, $20.3 \%$ among women with $10-12$ years of education and $19.6 \%$ among women $\leqslant 9$ years of education. After adjustment for psychological job demand, low education showed a trend towards low birth weight at a $\mathrm{p}$ value of 0.05 .

Multiple linear regression revealed that each SES indicator explained less than $1 \%$ of the total variation in birth weight. When combining maternal age, parity, gestational age, sex of

newborn, obstetrical complications and number of antenatal care visits as explanatory variables, $r^{2}$ reached $36 \%$. The partial $F$ test, when each SES indicator was added to the maternal characteristics, was not statistically significant. In the multivariate model including each SES indicator, a statistically significant low birth weight was seen for nulliparous ent with obstetrical complications, new born of female sex and for women with few antenatal care visits. Analyses restricted to deliveries, which took place from gestational weeks 38 to 42 were also performed and provided similar results (data not shown).

Table 5 shows no clear association between family SES, maternal education, maternal occupation and LBW adjusted for gestational age but a borderline significant level with unemployment. Women in the second level of each social indicator generally had the lowest proportion of LBW, but the associations were not statistically significant. Table 5 shows no constent association betwen socioeconomic indicators and SGA or premat wa only significantly associated with women who were exposed to a high psychological job demand. The crude odds ratio between each SES indicator and LBW adjusted for gestational age or SGA or prematurity showed no association (data not shown) but generally reduced after adjustment for other covariates;

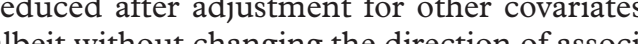
beit without changing the direction of association. 
Table 5 Odd ratios ${ }^{\star}$ for $L B W, S G A$, and preterm delivery by socioeconomic indicators in women who gave birth to singletons: five separate analyses by logistic regression

\begin{tabular}{|c|c|c|c|}
\hline Socioeconomic indicator & $L B W(95 \% C I)$ & $S G A(95 \% C I)$ & Preterm $(95 \%$ CI) \\
\hline \multicolumn{4}{|c|}{ Family socioeconomic status $\dagger$} \\
\hline & 1 & 1 & 1 \\
\hline & $0.7(0.3,1.7)$ & $1.5(0.3,7.4)$ & $1.1(0.4,3.3)$ \\
\hline & $0.9(0.4,2.2)$ & $2.3(0.5,10.9)$ & $1.1(0.4,3.3)$ \\
\hline 4 & $0.8(0.4,1.7)$ & $0.9(0.2,4.1)$ & $0.9(0.3,2.4)$ \\
\hline \multirow{2}{*}{\multicolumn{4}{|c|}{$\begin{array}{l}\text { unemployed } \\
\text { Maternal education ( } y \text { ) }\end{array}$}} \\
\hline & & & \\
\hline & 1 & ref & 1 \\
\hline $13-15$ & $0.7(0.2,2.5)$ & ref & $0.8(0.2,3.9)$ \\
\hline 10-12 & $0.6(0.2,1.5)$ & $0.7(0.2,2.5)$ & $1.2(0.4,3.7)$ \\
\hline$\leqslant 9$ & $0.8(0.3,1.8)$ & $0.6(0.2,2.0)$ & $0.9(0.3,2.8)$ \\
\hline \multicolumn{4}{|l|}{ Maternal occupation } \\
\hline Profession & & 1 & 1 \\
\hline Clerical & $0.8(0.2,3.0)$ & $1.0(0.1,7.0)$ & $1.4(0.3,6.6)$ \\
\hline Trader & $0.7(0.2,1.9)$ & $0.7(0.1,4.2)$ & $1.4(0.4,5.2)$ \\
\hline Agriculturer & $1.2(0.5,3.0)$ & $0.7(0.1,3.4)$ & $1.1(0.3,4.0)$ \\
\hline Labourer & $0.8(0.3,2.1)$ & $0.8(0.2,4.3)$ & $1.8(0.5,6.5)$ \\
\hline Service & $1.4(0.5,4.0)$ & $2.6(0.5,12.9)$ & $1.6(0.4,6.8)$ \\
\hline \multirow{2}{*}{\multicolumn{4}{|c|}{ Family income (baht) }} \\
\hline & & & \\
\hline $10001-20000$ & & 1 & \\
\hline 5001-10 000 & $1.1(0.6,1.7)$ & $1.9(0.7,5.2)$ & $0.9(0.5,1.8)$ \\
\hline$\leqslant 5000$ & $1.2(0.7,2.2)$ & $1.4(0.5,4.0)$ & $0.9(0.5,1.7)$ \\
\hline \multicolumn{4}{|c|}{ Maternal work exposure characteristics $\ddagger$} \\
\hline \multicolumn{4}{|c|}{ Physical job demand } \\
\hline Low & 1 & 1 & \\
\hline Moderate & $1.8(0.9,3.7)$ & $0.8(0.3,2.2)$ & $0.7(0.4,1.4)$ \\
\hline High & $1.6(0.6,4.1)$ & $1.8(0.5,6.1)$ & $1.4(0.6,3.6)$ \\
\hline \multicolumn{4}{|c|}{ Psychological job demand $\Omega$} \\
\hline Low & & 1 & \\
\hline Moderate & $0.8(0.4,1.8)$ & $0.4(0.1,2.9)$ & $0.9(0.4,2.4)$ \\
\hline & $1.1(0.6,2.0)$ & $3.1(1.4,6.9)$ & $1.0(0.5,2.1)$ \\
\hline \multicolumn{4}{|l|}{ Work control§ } \\
\hline High & & & \\
\hline Moderate & $0.7(0.3,1.4)$ & $0.5(0.1,1.9)$ & $1.3(0.5,2.9)$ \\
\hline Low & $0.7(0.4,1.2)$ & $0.9(0.3,2.2)$ & $0.9(0.4,1.9)$ \\
\hline
\end{tabular}

*Adjusted OR for parity, maternal height, maternal age, obstetrical complications, baby sex, maternal weight at delivery day, number of antenatal care visits and gestational week. †Family socioeconomic status; $1=$ High $2=$ pper middle $3=$ Middle $4=$ Low. ‡Each analysis on work erate $=51$ th -75 th percentile, High $=\geqslant 76$ th percentile

To further explore the association between SES indicators and birth weight at different birth weight categories, polytomous regression on four birthweight groups $(\leqslant 2500 \mathrm{~g}, 2501$ $3000 \mathrm{~g}, 3001-3500 \mathrm{~g}$ and $\geqslant 3501 \mathrm{~g}$ ) was performed using $2501-3000 \mathrm{~g}$ as reference. None of these analyses provided significant new findings (data not shown).

Discussion

The results suggest that socioeconomic indicators measured by family socioeconomic status, maternal education and maternal occupation were not strongly associated with fetal growth or preterm delivery in this setting. Low income was, however associated with low birth weight, and the lowest birth weight was seen when the fathers were unemployed. Nulliparous, young age, short stature, previous history of LBW or preterm delivery, obstetrical complications, female infants, low maternal weight at delivery and low utilisation of health care service correlated with birth weight as expected from previous studies and most of the association with SES indicators were explained by these factors. A high job demand and low work control showed no association with mean birth weight. None of the socioeconomic indicators were statistically associated with the dichotomous outcome such as LBW, SGA and preterm delivery except psychological job demand. These findings indicate that SES is not strongly associated with reduced fetal growth or preterm delivery in this study in Thailand.
KEY POINTS

- Disadvantaged social class has been reported to be associated with poor pregnancy outcome.

- A country undergoing rapid industrialisation often increases social gaps and Thailand is in the phase of rapid transition

- No significant impact of SES was seen for fetal growth or preterm delivery when using five different socioeconomic indicators (SES); education, income, occupation, socioeconomic status and work exposure characteristics

In Spain, family income was found to be a strong determinant of infant mortality in the ate 1970 s, but health care indicators became more important in the $1980 \mathrm{~s} .{ }^{22}$ For birth weight, Cramer ${ }^{26}$ showed that women with higher income had larger babies. A study in Malaysia $^{27}$ found that income correlated with birth weight. Furthermore, income seemed to modify the risk associated with short interbirth intervals, where the risk of fetal malnutrition probably is highest.

Some recent studies in industrialised countries suggested that low SES is not associated with LBW after adjustment for obstetrical factors and smoking ${ }^{16} 2^{28-30}$ but not all. ${ }^{10}{ }^{13} 31$ The lack of effect of occupational job demand and job control is consistent with results from other studies both from industrialised ${ }^{32-34}$ and newly industrialised countries ${ }^{35}$ Smoking cigarettes rining are les likely to be confounders of any importance in Thailand as less than $2 \%$ of the women smoked or drank alcohol in our study group.

Several studies in developing countries show that poor social status is linked to lack of basic social needs and poor access to health care, whereas basic social needs are probably met in most social groups in developed countries. Low maternal weight, poor obstetrical history, lack of antenatal care, anaemia and hypertension were significant, independent risk factors for both preterm and term LBW infants in India, and after adjusting for these factors, SES factors were not associated with these outcomes ${ }^{36} \mathrm{Kramer}^{37}$ concluded that SES had on intrauerine growth in developed and developing countries, except for what could be attributable to nutritional or behavioural factors.

In contrast with previous studies in Thailand, we found no significant and independent associations between SES indicators and LBW, SGA and preterm delivery, ${ }^{38}{ }^{39}$ which may be because of under-ascertainment of the most well to do women who probably seek help at private antenatal care units. However, data on pregnancy outcome from 560 women who consulted private antenatal clinics did show similar rates for LBW (9.8\%) and SGA $(2.5 \%)$. The low proportion of SGA according a 25 year old standard indicates that bing weight has increased over time, which may be attributable to better social conditions for most 
of the population. This study was conducted in an urbanised and industrialised area where antenatal care is run by hospitals rather than by primary health care centres as in the rural areas. Moreover, the occupational profile, nutritional status, antenatal care service, biological and work related characteristics are different in this study population compared with other parts of Thailand and the results need not be generalisable to the entire country.

A country undergoing rapid industrialisation often increases social gaps. At present we found no large impact on reproductive health, but this may change in the future. On the other hand, rapid development may soon overcome the health hazards associated with poverty if all benefit from the development. Health and social condition should be monitored closely and the results should be used in public health planning in Thailand.

Funding: this project was financed by a grant from the Danish Ministry of Foreign Affairs, Denmark and under the support of the Thailand Research Fund (TRF)

\footnotetext{
1 McCormick MC. The contribution of LBW to infant mor-

tality and childhood morbidity. $N$ Engl F Med 1985;312:82-
90 .
2 Antonovsky A, Bernstein J. Social class and infant mortality.
Soc Sci Med 1977:11:453-70.

Soc Sci Med 1977;11:453-70.
3 Dunn HG. Social aspects of LBW. Can Med Assoc $\mathcal{F}$ 1984;130: $1131-40$.
4 Joffe M. Social inequalities in LBW: Timing of effects and 4 Joffe M. Social inequalities in LBW: Timing of effects and
selective mobility. Soc Sci Med 1989;28:613-19. 5 Rodriguez C, Regidor E, Gutierrez-Fisac JL. LBW in Spain associated with sociodemographic factors. I Epidemiol
Commmnity Health 1995;49:38-42. 6 Baird D. Social influences on reproductive performance. $f$

作 review of psychosocial
Med 1990;30:553-68.

8 Mackenbach JP. Socio-economic health differences in the Netherlands: A review of recent empirical findings. Soc Sci 9 Nordstrom ML, Cnattingius S. Effects on birthweights maternal education, socio-economic stats and wo

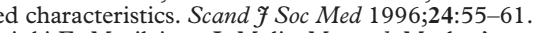
class and perinatal problems in a low-problem area. Int $f$ Epidemiol 1990,19:983-90.
Parker JD, Schoendofy a Parker JD, Schoendorf KC, Kiely JL. Associations between
measures of socioeconomic status and LBW, small for gestational age, and premature delivery in the Unite 12 Abramson JH, Gofin R, Habib J, et al. Indicators of social class. Soc Sci Med 1982;16:1739-46.
13 Arntzen A, Samuelsen SO, Magnus P, et al. Birthweight 3 Arntzen A, Samuelsen SO, Magnus P, et al. Birthweight
related to social indicators in Norway. European fournal of Public Health 1994;4:92-7.

14 Brooke OG, Anderson HR, Bland JM, et al. Effects on
} birthweight of smoking, alcohol, caffeine, socioeconomic
factors, and psychosocial stress. $B M \mathscr{F} 1989 ; 298: 795-801$.
15 Seidman DS, Samueloff A, Yosef SM, et al. The effect of maternal age and socioeconomical backgroun
outcome. Int $f$ Gynaecol Obstet 1990;33:7-12.

16 Morrison J, Naiman JM, Williams GM, a d. Socioeconomic status and pregnancy outcome. An Australia study. Br f Obstet Gynaecol 1989;96:298-307.

Peacock JL, Bland JM, Anderson HR. Preterm delivery: effects of socioeconomic factors, psychological stres,
smoking, alcohol, and caffeine. $B M Y 1995 ; 311: 531-5$ 8 Chase HC. Infant mortality and weight at birth: 1960 United States birth cohort. Am I Public Health 1969;59

9 Saugstad LF. Weight of all births and infant mortality. $\mathcal{F} E p i-$

(the "Barker hypothesis"). BMÆ 1995;310:411-12 Barker DJP, ed. Fetal and infant origins of adult disease. Plymouth, Great Britain: Latimer Trend, 1993.

, Banco JI, Delgado-Rodriguez M, et al. Influence of socioeconomic and health care development on infant
and perinatal mortality in Spain 1975-86. I Epidemid Community Health 1993;47:260-4.

3 Nittayaramphong S, Tangcharoensathien V. Thailand: of control? Health Policy and Planning 1994;9:31-40.

4 Karasek R, ed. Fob content questionnaire and user's guide. Lo Angeles: University of Southern California, Department o Liberatos P, Link BG, Kelsey JL. The measu;

class in epidemiology. Epidemiol Rev 1988;10:87-121.

Cramer JC. Racial and ethnic differences in birthweigh The role of income and financial assistance. Demography DaVanzo J, Ha

Butz WP. Assessing socioeconomic ferences and changes over time. Soc Sci Med 1984;18:387404.

Peters TJ, Golding J, Butler NR, et al. Plus ca change: preGynecol 1983;90:1040-5

9 Lumley J, Correy JF, Newman NM, et al. Cigaret smoking, alcohol consumption and fetal outcome 33-40. 1982 to 1986. Aust $\mathcal{P}$ Public Health 1992;16:15-

Olsen J, Frische G. Social differences in reproductive

Health. Scand 7 Soc Med 1993,21:90-7.

pregnancy: A causal link or recall bias? Am $\mathcal{F}$ Epidemiol 1992;135:302-11.

3 Homer CJ. Work-related psychosocial stress and risk of pre4 Henriksen TB, Hedegard M, Secher NJ. The rel

between psychosocial job strain and preterm delivey LBW for gestational age. Int $\mathcal{F}$ Epidemiol 1994;23:764-74 Mireles PC, Harlow SD, Carrillo SC. The risk of premat effects of working conditions and antenatal leave. Am Public Health 1996;86:825-31. Mavalankar DV. Gray RH, Trived CR. Risk factors for pre-
term and term LBW in Ahmedabad, India. Int $₹$ Epidemiol 1992;21:263-72.

77 Kramer MS. Determinants of LBW: methodological assess-

ment and meta-analysis. Bull World Health Organ 1987;65:
$663-73$.
8 Chumnijarakij T, Nuchprayoon T, Chitinand S, et al. Maternal risk factors for LBW newborn in $\mathrm{T}$, Chitinand $\mathrm{S}$, et al Assoc Thai 1992;75:445-52.

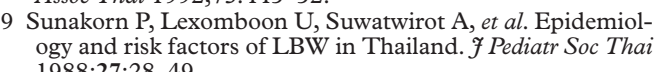

